\title{
Worldwide variations in the prevalence of atopic symptoms: what does it all mean?
}

\section{J O Warner}

University of Southampton/Southampton General Hospital, Southampton, Hampshire, UK

Introductory article

\section{Worldwide variation in prevalence of symptoms of asthma, allergic rhinoconjunctivitis, and atopic eczema: ISAAC}

\section{The International Study of Asthma and Allergies in Childhood (ISAAC) Steering Committee}

Background. Systematic international comparisons of the prevalences of asthma and other allergic disorders in children are needed for better understanding of their global epidemiology, to generate new hypotheses, and to assess existing hypotheses of possible causes. We investigated worldwide prevalence of asthma, allergic rhinoconjunctivitis, and atopic eczema. Methods. We studied 463801 children aged 13-14 years in 155 collaborating centres in 58 countries. Children self-reported, through one-page questionnaires, symptoms of these three atopic disorders. In 99 centres in 42 countries, a video asthma questionnaire was also used for 304796 children. Findings. We found differences of $\mathbb{Q}$ between 20-fold and 60-fold between centres in the prevalence of symptoms of asthma, allergic $\overrightarrow{\overrightarrow{0}}$ rhinoconjunctivitis, and atopic eczema, with four-fold to 12-fold variations between the 10th and 90th percentiles for the different disorders. For asthma symptoms, the highest 12-month prevalences were from centres in the UK. Australia, New Zealand, and Republic of Ireland, followed by most centres in North, Central, and South America; the lowest prevalences were from centres in several Eastern European countries, Indonesia, Greece, China, Taiwan, Uzbekistan, India, and Ethiopia. For allergic ※ rhinoconjunctivitis, the centres with the highest prevalences were scattered across the world. The centres $\frac{\sigma}{3}$ with the lowest prevalences were similar to those for asthma symptoms. For atopic eczema, the highest prevalences came from scattered centres, including some from Scandinavia and Africa that were not $\risingdotseq$ among centres with the highest asthma prevalences; the lowest prevalence rates of atopic eczema were 9 similar in centres, as for asthma symptoms. Interpretation. The variation in the prevalences of asthma, allergic rhinoconjunctivitis, and atopic-eczema symptoms is striking between different centres throughout the world. These findings will form the basis of further studies to investigate factors that $\stackrel{\mathcal{N}}{.}$ potentially lead to these international patterns. (Lancet 1998;351:1225-32)

Asthma is the commonest chronic disease affecting children and, with the related atopic disorders of eczema and allergic rhinitis, constituted a third of all chronic disorders even 30 years ago. The consequences in terms of health education and career attainment and even occasionally survival must be a cause for major public concern. Furthermore, the health economic burden on communities is escalating at an alarming rate. Despite these remarkable statistics, resourcing of research into the causes of these disorders is small by comparison with that devoted to the study of cardiovascular diseases or cancers. One might ask whether this is because our politicians and senior administrators feel themselves to be more likely to suffer from the latter and ignore atopic diseases because they have their major impact on children and young adults. It is interesting to speculate on how much more effort would be put into $\frac{0}{0}$ elucidating causes of a disorder which increased in $\overrightarrow{\mathbb{D}}$ prevalence by $1 \%$ per year and affected predominantly $\frac{\Omega}{\mathbb{D}}$ the middle aged and elderly. There is increasing evidence that asthma and related atopic disorders are increasing at this rate but, of course, for the present at least, affect $\delta$ the young.

While there might be some dispute about the exact rate of increase in the prevalence of atopic diseases and whether some of the increase might be apparent rather than real because of changes in diagnostic ascertainment, there is no doubt that the diseases are immensely common. However, there is a substantial body of evidence from epidemiological surveys in the 
United Kingdom that prevalence has increased significantly in the school age population. Thus, in children in Aberdeen doctor-diagnosed asthma increased from $4.1 \%$ in 1964 to $10.2 \%$ in $1989 .{ }^{2}$ By 1994 this figure had reached $19.6 \%{ }^{3}$ Similarly, in South Wales asthma increased from $6 \%$ to $12 \%$ in 12 year old children between 1973 and 1988 and in the British contribution to the International Study of Asthma and Allergies in Childhood (ISAAC) amongst 12-14 year olds, selfreported asthma was $20.9 \%$ in 1996.5 The Aberdeen figures for hay fever and eczema in 1964 and 1989 were $3.2 \%$ and $11.9 \%$, and $5.3 \%$ and $12 \%$ respectively. In South Wales the figures for hay fever and eczema in 1973 and 1988 were $9 \%$ and $15 \%$, and $5 \%$ and $16 \%$, respectively ${ }^{4}$ The British ISAAC figures from 1996 gave prevalences of hay fever and eczema in the previous 12 months of $18.2 \%$ and $16.4 \%$, respectively. These unprecedented increases in prevalence could be classified as an epidemic.

\section{International Study of Asthma and Allergies in Childhood (ISAAC)}

While successive studies have reported widely varying prevalence rates for the atopic diseases in several countries around the world, there have been few studies using standardised approaches in different parts of the world. The European Community Respiratory Health Survey (ECRHS) has investigated asthma and allergic rhinitis in adults aged 20-44 years but has concentrated as might be expected by the title, on Western Europe. ISAAC, a concept originally conceived by Dr Innes Asher, a paediatric chest physician in Auckland, New Zealand, has established a standardised methodology for comparing the prevalence and severity of asthma and related atopic diseases in children both within and between countries throughout the world 8 Phase I of this programme is now complete and has involved a compulsory core sampling from all participating centres of children aged 13-14 years from 56 countries involving 155 collaborating centres and just over half a million children. Some centres also extended their study to a younger age group of 6-7 year olds. The only difference between the two was that the children in the older age group answered the questions themselves while for the younger children the questionnaire was completed by the child's carers.

The ISAAC Steering Committee set themselves the task of describing prevalences of the atopic diseases and their symptoms, and to make some estimate of severity. Strenuous attempts were made to validate at least the asthma questionnaire by employing a video showing clinical signs and symptoms of asthma, followed by the questionnaire. The rank correlation coefficient between centre prevalences from written and video questionnaires was $0.76(\mathrm{p}<0.0001)$. The prevalence of asthma symptoms on the video questionnaire was lower than that reported on the written questionnaire, probably because the video tended to seek information about more severe symptoms such as wheezing at rest while the written questionnaire asked about any wheezing. This, however, provides one of the only true validations of an internationally employed questionnaire. Nevertheless, this still does not totally overcome some problems related to language. In some countries there is no appropriate term for symptoms such as wheezing which might account for some of the differences found. However, 20-fold to 60-fold differences between centres in the prevalence of symptoms of asthma, allergic rhinitis, and atopic eczema is clearly way beyond any minor issues related to methodology. Furthermore, there are significant similarities between the results of the adult ECRH $\$$ and ISAA $\$$ studies. The highest prevalence rates for asthma occurred in the UK, Australia, New Zealand, and the Republic of Ireland, followed by centres in North, Central and South America, with very ? low prevalence rates in East European countries, the Indian subcontinent, and the Far East.

By contrast to the prevalences of asthma, high pre- $\frac{\text { 음 }}{0}$ valences of allergic rhinoconjunctivitis symptoms were $\overline{\bar{n}}$ scattered throughout the world. It is perhaps more $\frac{\vec{\Phi}}{\otimes}$ difficult to disentangle methodological issues which $\frac{2}{8}$ might account for this. Discriminating non-allergic o causes of nasal and eye symptoms may well be very $\vec{\circ}$ much more difficult. However, for atopic eczema there $\overrightarrow{\vec{\omega}}$ was a slightly more consistent trend amongst the English $\stackrel{\omega}{\omega}$ speaking countries which had high prevalences, though $\vec{x}$ there were also high prevalences of eczema in some of Scandinavian and African countries which did not have high asthma rates. Those countries with low eczema 8 rates tended also to have low rates of asthma and allergic rhinoconjunctivitis. Again, validation of the questions $\$$ is lacking. There are a number of other causes of itchy rash coming and going over a period of months, and this may be a problem in African countries in particular where high rates of parasitic infection might have affected answers to the key questions on eczema.

\section{UK ISAAC study}

The UK ISAAC studyinvolved 27507 12-14 year olds across Great Britain.5 The 12 month prevalence of wheezing was $33.3 \%$, with a self-reported diagnosis of asthma in $20.9 \% ; 19.6 \%$ had received treatment for asthma in the previous year. The prevalence was highest $\cong$ in Scotland and there were slightly higher rates in non- $\overrightarrow{\overrightarrow{0}}$ metropolitan areas than in metropolitan areas $(35 \%$ vs $30.3 \%$ for wheeze in the previous 12 months). These differences were minor by comparison with those between countries. However, there was still a considerable difference between the reported prevalence of wheezing in the previous 12 months (33\%) and the reported asthma diagnosis of $20.9 \%$. One might ask whether this 3 . is underdiagnosis and consequently undertreatment, or $\delta$ whether the difference is due to alternative conditions. Much has yet to be established about "non-asthma wheezing". Certainly, from a reçent study in Norwa 10 and an old study in Australid ${ }^{11}$ there is a suggestion that non-asthma wheezers are, indeed, different from $\bar{N}$ diagnosed asthmatic subjects in terms of prevalence of $\sigma$ atopy and bronchial hyperresponsiveness. They are $\stackrel{N}{0}$ more similar to the non-wheezing population than to $\underset{\omega}{\omega}$ those with asthma. Thus, it would be inappropriate at this stage to assume that asthma remains a grossly underdiagnosed disorder.

The UK ISAAC survey also included information on home environment. It was clear that passive as well $\frac{7}{0}$ as active smoking was an important contributor to respiratory symptoms in adolescent children. Pets in- $\frac{\Omega}{\mathbb{D}}$ creased the risk of wheeze and rhinitis and the use of $\varrho$ unusual heating fuels also had an adverse effect. However, these items only accounted for a minority of the of risk factors associated with respiratory ill health ${ }^{12}$

Within the survey it was also possible to investigate the relationships between the three atopic disorders. Interestingly, the prevalence of severe wheeze was highest in children who also had perennial rhinoconjunctivitis rather than hay fever. There was also an association between severe wheezing and severe itchy flexural rash. Indeed, $43 \%$ of children with current 
wheeze also had one or more of the other atopic disorders. 9

Within the very tight age range of the UK survey it was possible to observe a small increase in the prevalence of wheeze in the previous 12 months in 14 year old girls compared with 12 year olds. This supports the proposal that asthma does increase in prevalence in girls as they progress through the teenage years, while in boys there appears to be a decrease in prevalence and, indeed, severity. There was also a significantly lower rate of asthma in adolescents born outside the UK compared with those born within the country (odds ratio 0.57, $\mathrm{p}<0.001)$. This again is consistent with the finding from many other countries that there is a considerable effect of environment in the antenatal and immediate postnatal period on the prevalence of asthma, even 12 years later.

\section{What does it all mean?}

Clearly, the primary aim for phase I of the ISAAC study was to identify whether there were indeed major differences in prevalence rates and this hypothesis has now been proven. Phase II of the study must attempt to investigate possible aetiological factors for these major differences and phase III will then repeat the surveys to assess trends in prevalences over time in different countries and, again, relate these changes to potential aetiological factors. This clearly forms the most important phase of the study, which will now perhaps begin to fulfil the expectations of the founders of ISAAC to identify causes and thereby interventions for preventing disease. In the ISAAC publication ${ }^{9}$ it is suggested that the studies of cancer epidemiology in the 1950 s and 1960s identified striking international differences which generated new hypotheses and highlighted previously unknown risk factors for cancers. To what extent this has had an impact on subsequent prevention is a moot point.

Clearly, however, there is room for considerable speculation on likely explanations for the remarkable variations in prevalence of atopic disease and changes that have occurred over time, particularly in the English speaking world.

\section{Hypotheses}

Over recent years a number of highly credible hypotheses have been proposed to explain the remarkably high prevalence of allergic disorders. All have some credibility but hitherto have not been confirmed by the acid test of showing that an intervention that addresses the basic hypothesis changes prevalence.

\section{ALLERGENS}

As these diseases are primarily triggered or incited by exposure to allergens, it is tempting to speculate that a change in allergen exposure at various stages in life has been the primary reason for changing prevalence. Certainly there is some limited evidence that alterations to the domestic environment worldwide have increased the opportunity for mites to replicate. The use of energy saving measures such as double glazing, draught exclusion, and rigid control of indoor temperatures has reduced air exphanges and optimised conditions for mite replication ${ }^{13}$ However, in many areas of the world where asthma is still common, house mites are clearly not the cause. In such areas alternative potential causative allergens have been identified-for example, Alternaria mould in Tucson, Arizon $1^{14}$ and the allergens of cat and dog in Scandinavian countries.17 This suggests that individuals susceptible to developing atopic diseases will become sensitised to whatever allergens are prevalent in the environment and therefore little will be gained by allergen avoidance in the primary prevention $\frac{0}{2}$ of disease. Indeed, this issue was discussed in a recent $\stackrel{x}{.}$ leading article ${ }^{16}$ Under such circumstances it seems $\vec{\Rightarrow}$ improbable that changing allergen exposure in early life can account for increasing prevalences of disease.

The presence of allergy, particularly to house dust $\frac{\bar{O}}{\mathrm{~m}}$ mite, is clearly a very strong risk factor for subsequent asthma as, indeed, is allergy to grass pollen and cat ${ }^{17}$ Odds ratios for current asthma prevalence increased progressively in mite sensitised children with the level $\vec{\circ}$ of mite exposure in a study reported from New South $\overrightarrow{\vec{\omega}}$ Wales, Australia ${ }^{18}$ However, no study has hitherto $\stackrel{\omega}{\omega}$ shown that any strategy of aeroallergen avoidance has $\vec{x}$ prevented the development of atopic disease. Here, the or difficulties lie in establishing whether there is a limited risk period during which allergen avoidance might be $\bigcirc$ effective in permanently preventing sensitisation and $\infty$ disease. As occupational allergen exposure can induce disease at any stage in life, this could be a strong argument against environmental manipulation at this level having any lasting effect.

It has been shown that sensitisation can occur in intrauterine life and it is just possible that, at least for $\frac{c}{\infty}$ a proportion of atopic subjects, prevention of sens- $\overrightarrow{\vec{\theta}}$ itisation at this stage will have an impact throughout $\notin$ life ${ }^{19}$ Furthermore, there are studies suggesting that early exposure to allergen such as to cat and dog dander in the first year of life produces a higher probability of sensitisation and asthma throughout childhood.2. ${ }^{2}$ Furthermore, migration studies have shown that individuals retain the asthma prevalence rates of their $\unrhd$ community of birth rather than of the country to which $\overrightarrow{\overrightarrow{0}}$ they migrate and indeed, this was apparent from the UK ISAAC data 5 However, not all studies have been able to demonstrate this effect ${ }^{21}$ With these conflicting data it is perhaps not surprising that aeroallergen avoidance studies have hitherto produced conflicting results, with only limited and transient effects on atopic dermatitis but not asthma 22

\section{POLLUTION}

It has become fashionable for the media to blame $\frac{7}{2}$ outdoor air pollutants as the cause for increasing asthma and related atopic disorders. While various pollutants $\sigma$ can incite asthma, there is no evidence to support the $\stackrel{N}{\circ}$ assertion that they induce the disease. Indeed, the East $\underset{\omega}{\mathbb{N}}$ Germany/West Germany comparisons suggest quite the opposite. In somewhat more polluted East German 0 cities asthma and allergy are-less prevalent than in the $\mathbb{\Phi}$ cleaner West German cities ${ }^{23}$ Whether this relates to pollution or to some other aspect of lifestyle remains to be established.

\section{ENVIRONMENTAL TOBACCO SMOKE}

It is, important to note that maternal smoking may be an important factor in inducing transient wheezing 을 illnesses in early life. This is likely to be predominantly? an effect on lung growth in utero which impairs function transiently in infancy ${ }^{24}$ However, the extent to which parental cigarette smoking influences the development of atopy has been extensively discussed and it is doubtful that it has much, if any, impact. ${ }^{25}$ 


\section{AFFLUENCE}

It is very apparent from studying the different prevalence rates of atopic diseases worldwide that the primary association is with affluence. What component of the more affluent lifestyle has had an effect remains to be established. The "Barker hypothesis", which has introduced a new paradigm into medicine relating fetal growth and nutrition to adult diseases, could be applied to atopic disorders. The Barker group and one other have identified an association between birth head circumference and subsequent raised $\operatorname{IgE}$ level $5^{20}$ and asthma. ${ }^{27}$ Their hypothesis is that affluence and good nutrition in young women programmes the fetus to adopt a high growth trajectory. However, the nutrient demands of a rapidly growing fetus in the third trimester can sometimes not be met as the placental capacity is exceeded and, therefore, paradoxically these fetuses become relatively poorly nourished. A brain-sparing reflex facilitates continuing head and brain growth at the expense of the rest of the body. Rapidly dividing tissues, such as those in the immune system, suffer first and this could upset the balance in a way that increases the risk of allergy. This hypothesis is certainly worthy of further investigation to establish which components of the diet might be involved.

\section{DIET}

There are, of course, a number of dietary factors which may be implicated in increasing the risk of allergic disease. A very coherent hypothesis proposed by Seaton et $a l$ is that the increasing prevalence of allergic diseases is inversely related to the decrease in dietary antioxidant intake in communities. This relates to the reducing use of fresh vegetables and fruits ${ }^{28}$ Indeed, a recent British survey by Butland et $\mathrm{a}^{20}$ in part supports this concept; after accounting for the effect of smoking they reported that low fresh fruit intake was associated with frequent wheeze and speech limiting attacks in 33 year old subjects. This suggests that diet might have more influence on severity of disease than on its prevalence.

It is also possible that other factors such as dietary fatty acids might be involved. Studies have shown associations between consumption of oily fish and reduced risk of asthma ${ }^{30}$ Phospholipids, being the principal component of cell membranes, are certainly at the heart of cell biology and are involved not only with the arachadonic acid pathway leading to generation of prostaglandins and leukotrienes but also with signal transduction. Minor alterations in membrane phospholipids could have a major impact on immune cell function ${ }^{31}$ Again, controlled intervention studies are awaited with great interest.

\section{HYGIENE HYPOTHESIS}

Perhaps the most credible hypothesis that has been mounted in recent years has been termed the "hygiene hypothesis". This was first proposed by Strachan in 1989.32 He demonstrated an inverse relationship between birth order in families and prevalence of hay fever and proposed that infections in early infancy brought home by older siblings might prevent sensitisation. Many subsequent studies have supported these observations. Indeed, the East German/West German comparisons might be taken to show the same thing in that pollution in East Germany was associated with a higher frequency of respiratory infections diagnosed as bronchitis which, in turn, was associated with less allergy. ${ }^{23}$

Clearly there is a biological credibility to this hypo- thesis in that infection will tend to induce a T lymphocyte helper 1 (Th1) subtype response promoting the production of interleukin 2 (IL-2) and interferon gamma (IFN- $\gamma$ ) which, in turn, would downregulate the Th2 $\mathrm{J}$ response associated with allergy where IL-4, IL-5, IL- 응 10 , and IL-13 are generated. The Th2 response in $\stackrel{x}{.}$ turn has a downregulatory effect on Th1 activity. This $\vec{F}$ hypothesis has been further supported by a number of $\frac{\mathscr{O}}{0}$ studies. In Japan an inverse relationship was found 듬 between tuberculin responsiveness and allergy. ${ }^{33}$ This is $\overline{\bar{c}}$ further reinforced by observations that BCG can sup- $\frac{\widehat{\Phi}}{\alpha}$ press local Th2 immune responses in the murine model.$^{34}$ Similar inverse relationships have been found क between allergy and hepatitis $\mathrm{A}^{3}$ and measles infection $\vec{\circ}$ in childhood 36 However, there are conflicting data $\overrightarrow{\vec{\omega}}$ which have failed to show that either measles vaccination ${ }^{37}$ or $\mathrm{BCQ}^{38}$ produce any significant effect on $\overrightarrow{\vec{x}}$ subsequent development of atopy. It appears, therefore, $\stackrel{x}{\mathrm{u}}$ that only natural infection in childhood is sufficiently powerful to modify immune responses. This is not, 8 however, deterring further work in this area to develop $\infty$ potential Th1 promoting immunoadjuvants for the $\$$ treatment of allergic disorders. BCG and heat killed $\rho$ Listeria monocytogenes are currently the main focuses of work, though in the longer ferm DNA vaccines may prove to be more effective 39 Again, human trials will be awaited but circumspection is required because extra- $\frac{\Gamma}{\omega}$ polation from murine models has in the past produced $\vec{\overrightarrow{ }}$ repeated disappointments ${ }^{40}$ It is perhaps more credible $ॄ$ to consider whether the normal gut microbial flora in infancy might have an immunising effect, reducing the prevalence of atopy. Certainly there has been a change in such flora in affluent communities ${ }^{41}$

\section{Genetic and environmental diversity}

Having considered all the above hypotheses, it is important to note the remarkably greater prevalence of allergic disorders amongst the English speaking communities worldwide. 9 This cannot be explained by any of the hypotheses when compared, for example, with lower prevalences in highly affluent, non-polluted en- $\underset{\dot{\sigma}}{-}$ vironments in Scandinavia. English speaking com- 3 . munities have a far broader genetic diversity in terms $\dot{\delta}$ of ethnic backgrounds than those communities with low prevalences of atopy. One could speculate on whether $ᄋ$ this, together with the enormously increased diversity of environment to which the English speaking people have exposed themselves, might be the real explanation $\bar{N}$ for varying and changing prevalences.

Amongst communities that have been relatively cir- $\tilde{O}$ cumscribed and isolated, the range of major histo- $\tilde{\omega}$ compatibility complex genes is limited. However, it is enormously diverse in the UK, Australia, New Zealand, and North America. As a consequence, there is less $\mathbb{\Phi}$ limitation on the capacity to present antigen. This increased diversity of genes influencing allergen pre- $\frac{T}{0}$ sentation, together with an enormous increase in the $\overrightarrow{\mathbb{D}}$ range of allergens to which individuals have been exposed over the last few decades, means that there is a 2 far higher probability that an allergic reaction will be induced.

The impact of this genetic diversity may well have its major effects in utero. Successful pregnancy has been 을 viewed as a phenomenon of Th2 lymphocyte upregulation ${ }^{42}$ Certainly we have found a very marked upregulation of cytokines associated with a Th2 response in various cells within the decidual tissues. Thus, amniotic fluid contains high levels of IL-10 and prostaglandin $\mathrm{E}_{2}$ with negligible quantities of IFN- $\gamma$ and 


\section{LEARNING POINTS}

* There are 20-fold to 60-fold differences in prevalence of symptoms of asthma, allergic rhinitis, and atopic eczema between centres located in various parts of the world.

* Highest prevalence rates for asthma occur in the English speaking countries of UK, Australia and New Zealand, with very low rates in Eastern Europe, the Indian subcontinent, and $\underset{\Rightarrow}{\Rightarrow}$ the Far East.

* Allergic rhinoconjunctivitis prevalence rates vary more inconsistently throughout the world while atopic eczema follows asthma more closely, though with unexpectedly high rates in some Scandinavian and African countries.

* UK data indicate a 12 month period prevalence of wheezing of $33.3 \%$ and self-reported asthma diagnosis in $20.9 \%$ amongst $12-14$ year olds.

* Variations across Britain are small with higher rates in non-metropolitan areas and in Scotland rather than England.

* Many hypotheses have been mounted to explain the high and increasing prevalence rates of allergic disorders. None can totally explain the worldwide variations.

* The effects of increasing domestic allergen exposure because of tight homes, variations in pollution and tobacco smoke provide one attractive hypothesis.

* Associations with affluence and, therefore, perhaps diet and hygiene have been suggested as alternative hypotheses.

* Genetic and environmental diversity, particularly in English speaking communities, may explain some of the worldwide variations.

IL-2. Furthermore, amnion cells express IL-4 and cells within the placenta express IL-13. ${ }^{43}$ These cytokines will have the effect of downregulating Th1 responses in the mother to feto-paternal antigens. A Th1 response would result in a cellular reaction andeither miscarriage or intrauterine growth retardation ${ }^{42}$ That this phenomenon occurs in human pregnancy is perhaps best substantiated by the clinical observation that rheumatoid arthritis, a Th1 mediated disease, often improves appreciably during pregnancy only to relapse or, indeed, appear for the first time in the postpartum period. ${ }^{4}$ Furthermore, direct measurement of Th1 cytokines from stimulated peripheral blood mononuclear cells taken from healthy pregnant women has demonstrated reduction of Th1 function which has been proposed as the mechanism for improvement in rheumatoid arthritis ${ }^{4}$ However, not all women with rheumatoid arthritis improve with pregnancy and one remarkable study has suggested that improvement is dependent on the degree of mismatching in major histocompatibility complex genes. Thus, the materno-fetal disparity in alleles for HLA, DR and DQ antigens was far more common (26 of 34 pregnancies) in cases where the arthritis remitted or improved compared with those with continuing active disease (three of 12). This would suggest that the Th2 bias of pregnancy is actually switched on by genetic disparity between the mother and fetus ${ }^{46}$

It therefore would seem equally credible to propose that the greater the genetic disparity between mother and fetus, the greater the immunological drive towards allergy. Genetic diversity with far wider differences in MHC genes between mothers and their fetuses could set the stage for promoting the atopic phenotype. Certainly this is a hypothesis which would be relatively easy to investigate, though hitherto no studies have been conducted.

If genetic and environmental diversity is the ex- planation for the remarkably wide variations in prevalence of atopy throughout the world, then this casts a new and somewhat unfavourable light on the concept $\overrightarrow{\overrightarrow{0}}$ of hybrid vigour. It will be rather more difficult to identify intervention strategies that will have any impact on this phenomenon. Thus, in the end, the future of atopy prevention may well rest with immune modulation $\vec{\partial}$ and control of the environment. The mere fact that there are so many theories proposed to explain the $\stackrel{x}{\circ}$ allergy epidemic indicates that much more research is $\underline{3}$. required before there can be any expectation of achieving $\dot{\delta}$ a reduction in the prevalence of these immensely important diseases.

The author's group is in receipt of an NIH grant (HL618508-01) to investigate the early life origins of asthma and allergy. Thanks $N$ are due to Wendy Willcocks for typing the manuscript.

1 Schiffer CG, Hunt EP. Illness among children. Children's Bureau Publication No. 405. Washington, DC: US Department of Health Education and Welfare, 1963.

2 Ninan TK, Russell G. Respiratory symptoms and atopy in Aberdeen school children: evidence from two surveys 25 years apart. BMF 1992;

3 Omran M, Russell D. Continuing increase in respiratory symptoms and atopy in Aberdeen school children. BMF 1996;312:34.

4 Burr ML, Butland BK, King S, et al. Changes in asthma prevalence: $\vec{O}$ two surveys 15 years apart. Arch Dis Child 1989;64:1452-6.

5 Kaur B, Anderson HR, Austin J, et al. Prevalence of asthma symptoms, diagnosis, and treatment in 12-14 year old children across Great $\mathbb{\mathbb { D }}$ Britain (International Study of Asthma and Allergies in Childhood, ISAAC, UK). BMF 1998;316:118-24.

6 Austin JB, Kaur B, Anderson HR, et al. Hay fever, eczema and wheeze: a nationwide UK study (ISAAC - International Study of Asthma and 8 Allergies in Childhood). Arch Dis Child 1999 (in press).

7 European Community Respiratory Health Survey. Variations in the prevalence of respiratory symptoms, self-reported asthma attacks, and
use of asthma medication in the European Community Respiratory Health Survey (ECRHS). Eur Respir f 1996;9:687-95.

8 Asher MI, Keil U, Anderson HR, et al. International Study of Asthma and Allergies in Childhood (ISAAC): rationale and methods. Eur Respir F 1995;8:483-91.

9 The International Study of Asthma and Allergies in Childhood (ISAAC) Steering Committee. Worldwide variation in prevalence of symptoms of asthma, allergic rhinoconjunctivitis, and atopic eczema: ISAAC. Lancet 1998;351:1225-32. 
10 Nystad W, Stensrud T, Rijcken B, et al. Wheezing in school children is not always asthma. Pediatr Allergy Immunol 1999;10: (in press).

11 Williams $\mathrm{H}$, McNicol K. Prevalence, natural history and relationship of wheezy bronchitis and asthma in children. An epidemiological study. BMF 1969;4:321-5.

2 Burr ML, Anderson HR, Austin JB, et al. Respiratory symptoms and home environment in children: a national survey. Thorax 1999;54: 27-32.

13 van Bronswijk JEMH, Pauli G, eds. An update on long-lasting mite avoidance (dwelling construction, humidity management, cleaning). Aachen, Germany: GuT, 1996: 1-65.

14 Halonen M, Stern D, Wright AL, et al. Alternaria as a major allergen for asthma in children raised in a desert environment. Am $\mathcal{F}$ Respir Crit Care Med 1997;155:1356-61.

15 Kjellman B, Petterson R. The problem of furred pets in childhood atopic disease. Allergy 1983;38:65-73.

16 Helms PJ, Christie G. Prospects for preventing asthma. Arch Dis Child 1999;80:401-5.

17 ETAC Study Group. Allergic factors associated with the development of asthma and the influence of cetirizine in a double blind, randomised, placebo controlled trial: first results of ETAC. Pediatr Allergy Immunol 1998;9:116-24.

18 Peat JK, Tovey E, Toelle BG, et al. House dust mite allergens: a major risk factor for childhood asthma in Australia. Am 7 Respir Crit Care Med 1996;153:141-6.

19 Jones AC, Miles EA, Warner JO, et al. Peripheral blood mononuclear cell proliferative responses to mitogenic and allergenic stimuli during gestation. Pediatr Allergy Immunol 1996;7:109-16.

20 Warner JA, Little SA, Pollock I, et al. Influence of exposure to dust mite, cat pollen and fungal allergens in the home on primary sensitization in asthma. Pediatr Allergy Immunol 1990;1:79-86.

21 Strachan DP, Golding J, Anderson HR. Regional variations in wheezing illness in British children: effect of migration during early childhood. 7 Epidemiol Community Health 1990;44:231-6.

22 Hide DW, Matthews S, Tariq S, et al. Allergen avoidance in infancy and allergy at 4 years of age. Allergy 1996;51:89-93.

23 Von Mutius E, Martinez FD, Fritzsche C, et al. Prevalence of asthma and atopy in two areas of West and East Germany. Am F Respir Crit Care Med 1994;149:358-64.

24 Martinez FD, Wright AL, Taussig LM, et al and the Group Health Medical Associates. Asthma and wheezing in the first six years of life. N Engl 7 Med 1995;332:133-8.

25 Cook DG, Strachan DP. Summary of effects of parental smoking on the respiratory health of children and implications for research. Thorax. 1999;54:357-66.

26 Godfrey KM, Barker DJP, Osmond C. Disproportionate fetal growth and raised IgE concentration in adult life. Clin Exp Allergy 1994;24 $641-8$
27 Fergusson DM, Crane J, Beasley R, Horwood LJ. Perinatal factors and atopic disease in childhood. Clin Exp Allergy 1997;27:1394-400.

28 Seaton A, Godden DJ, Brown K. Increase in asthma: a more toxic eaton A, Godden DJ, Brown K. Increase in asthma: a more toxic environment or a more susceptible population. Thorax 1994;49:171-4. symptoms in young British adults: confounding or effect modification by smoking. Eur Respir 7 1999;13:744-50.

30 Hodge L, Salomy CM, Peat JK, et al. Consumption of oily fish and childhood asthma risk. Med $\mathcal{F}$ Aust 1996;165:137-40.

31 Yu G, Björkstén B. Polyunsaturated fatty acids in school children in relation to allergy and serum IgE. Pediatr Allergy Immunol 1998;9: $\overrightarrow{\vec{F}}$ 133-8.

32 Strachan DP. Hay fever, hygiene, and household size. BMf 1989;299: ত 1259-60.

33 Shirakawa T, Enomota T, Shimazu S, et al. The inverse association between tuberculin responses and atopic disorder. Science 1997;775: $77-9$.

34 Herz U, Gerhold K, Gruber C, et al. BCG infection suppresses allergic \ sensitization and development of increased airway reactivity in an animal model. F Allergy Clin Immunol 1998;102:867-74.

35 Matricardi PM, Rosmini F, Ferrigno L, et al. Cross-sectional retro- $\vec{\odot}$ spective study of prevalence of atopy among Italian military students with antibodies against hepatitis A virus. BMF 1997;314:999-1003.

36 Shaheen SO, Aaby P, Hall AJ, et al. Measles and atopy in Guinea-Bissau.

Lancet 1996;347:1792-6.
37 Golding J. Immunisations. In: Butler N, Golding J, eds. From birth to five. A study of the health and behaviour of Britains five year olds. Oxford: Pergamon, 1986: 295-319.

38 Alm JS, Lilia G, Pershagen G, et al. Early BCG vaccination and development of atopy. Lancet 1997:350:400-3.

39 Wills-Karp M. Potential use of Th-1 promoting immunoadjuvants in the treatment of allergic disorders. Postgraduate syllabus. Am Acad $\infty$ Allergy Asthma

40 Von Hertzen LC. The hygiene hypothesis in the development of atopy and asthma: still a matter of controversy? $Q \mathcal{F}$ Med 1998;91:767-71.

41 Holt PG, Sly PD, Bjorksten B. Atopy versus infectious diseases in 0 childhood: a question of balance. Pediatr Allergy Immunol 1997;8: 53-8.

42 Wegmann TG, Lin H, Guilbert L, et al. Bi-directional cytokine interactions in the maternal-fetal relationship: is successful pregnancy a Th-2 phenomenon? Immunol Today 1993;14:353-6.

ternal programming in asthma and allergy. Clin Exp Allergy 1998;28(Suppl.5):35-8.

44 Wilder RL. Hormones, pregnancy and auto-immune diseases. Ann NY $\vec{\bullet}$ Acad Sci 1998;840:45-50.

45 Russell AS, Johnston C, Chew C, et al. Evidence for reduced Thfunction in normal pregnancy: a hypothesis for the remission of rheumatoid arthritis. F Rheumatol 1997;24:1045-50.

46 Nelson JL, Hughes KA, Smith AG, et al. Maternal-fetal disparity in HLA class II allo-antigens and the pregnancy-induced amelioration of rheumatoid arthritis. $N$ Engl $\mathcal{F}$ Med 1993;329:466-71. 